\title{
Performance and Emission Analysis of a CI Engine in Dual Mode with LPG and Karanja Oil Methyl Ester
}

\author{
S. K. Acharya and S. P. Jena \\ Department of Mechanical Engineering, SOA University, Bhubaneswar, Odisha, India \\ Correspondence should be addressed to S. K. Acharya; saroj.acharya76@gmail.com
}

Received 8 June 2013; Accepted 18 August 2013

Academic Editors: V. Makareviciene, P. C. Pullammanappallil, and P. Tsilingiris

Copyright ( $) 2013$ S. K. Acharya and S. P. Jena. This is an open access article distributed under the Creative Commons Attribution License, which permits unrestricted use, distribution, and reproduction in any medium, provided the original work is properly cited.

The use of liquefied petroleum gas (LPG) is experimented with to improve the performance of a dual fuel compression ignition (CI) engine running on Karanja oil methyl ester (KOME) blends. Diesel is used as a reference fuel for the dual fuel engine results. During the experimentation, the engine performance is measured in terms of brake thermal efficiency (BTE) and brake specific fuel consumption (BSFC), and exhaust emission is measured in terms of carbon monoxide (CO), hydrocarbon (HC), and oxides of nitrogen $\left(\mathrm{NO}_{x}\right)$. Dual fuel engine with LPG showed a reduction in $\mathrm{NO}_{x}$ and smoke emission; however, it suffers from high HC and $\mathrm{CO}$ emission, particularly, at lower loads due to poor ignition. Comparison of performance and emissions is done for diesel and blends of KOME. Results showed that using KOME blends (10\% and $20 \%$ ) has improved the CI engine performance with a reduction in $\mathrm{HC}$ and $\mathrm{CO}$ emissions.

\section{Introduction}

The depleting reserves of petroleum and concern over high levels of pollutants in vehicular exhaust have motivated the researchers towards searching for alternative energy sources with renewable nature and less polluting effect [1]. The use of alternative gaseous fuel in CI engines in dual fuel mode is increasing due to their clean combustion compared to conventional liquid fuels as well as their relatively increased availability at attractive prices $[2,3]$. For substituting petroleum fuels used in internal combustion engines, fuel of bio-origin provides a feasible solution to the twin crises of "fossil fuel depletion" and "environmental degradation." Several researchers are actively pursuing utilization of nonedible oils for the production of biodiesel worldwide because of its cleaner burning nature $[4,5]$. Chemically, biodiesel is referred to as the mono-alkyl-esters of long-chain-fatty acids derived from renewable lipid sources. The principal advantages of biodiesel is that it suppresses the formation of sulphur dioxide, $\mathrm{CO}, \mathrm{HC}$, and PM emissions during the combustion process due to low sulphur, low aromatics, and the presence of oxygen-containing compounds. In addition, biodiesel has good ignition ability in engine due to its relatively high cetane number compared to that of conventional diesel fuel $[6,7]$. It is found that the lower concentrations of biodiesel blends improve the thermal efficiency. As the parameters at which the engines are operating, a blend up to $20 \%$ of biodiesel with diesel works well without any modification in the engine $[8,9]$. The potential benefits of using LPG in diesel engines are both economical and environment friendly [10]. With reduced energy consumption, the dual fuel engine shows a significant reduction in smoke density, $\mathrm{NO}_{x}$, and improved BTE [11]. Intake air throttling at low loads improves the brake thermal efficiency, and $\mathrm{HC}$ emission deteriorates with increase in percentage of LPG substitution [12]. In the present study, the effect of biodiesel blends over the performance and emission characteristics of a diesel engine in dual fuel mode was experimentally investigated with the variation of LPG flow rate.

\section{Experimentation}

The aim of the study is to establish a combination of biodiesel blends with gaseous fuel in dual fuel mode and to study 
TABLE 1: Engine specifications.

\begin{tabular}{lc}
\hline Manufacturer & Kirloskar \\
\hline Bore & $80 \mathrm{~mm}$ \\
Stroke length & $110 \mathrm{~mm}$ \\
Cubic capacity & $553 \mathrm{cc}$ \\
RPM & 1500 \\
BHP & $5 \mathrm{hp}$ \\
Compression ratio & $16.5: 1$ \\
Dynamometer type & Hydraulic \\
Cycle & 4 strokes \\
Injection pressure & 180 bar \\
\hline
\end{tabular}

the performance and emission characteristics of the engine with LPG as the gaseous fuel.

2.1. Experimental Setup. The engine used in this study is a Kirolskar made single cylinder, four stroke, water cooled diesel engine. The specifications of the engine are given in Table 1. Two separate fuel tanks are attached to the setup to store diesel and blends of biodiesel. The engine is coupled with a hydraulic dynamometer to measure the operating load. The engine is modified to dual fuel mode by attaching a vaporizer in between the LPG tank and LPG passage in the intake manifold. The inlet manifold of the engine is elongated by 3 feet, and the gas nozzle is drilled into the manifold. The flow of LPG is controlled by a needle valve. The pressure of the gas at inlet of vaporizer is measured by a pressure gauge. AVL 444 gas analyzer is attached to the exhaust to measure the emission parameters. The measurement range and accuracy of the gas analyzer are given in Table 2 . A pressurized closed circuit water cooling system is used to cool the engine. A digital type platform weighing machine having an accuracy of $1 \mathrm{mg}$ is used to measure LPG flow rate by weight difference method with an uncertainty of $1.2 \%$. The layout diagram of the experimental setup is shown in Figure 1. Initially the engine is tested using standard diesel at all loads to determine the engine performance and emission characteristics. The same procedure is repeated in dual fuel mode with increase in LPG flow rate for all loads. The mass fraction of LPG $(Z)$ is calculated by

$$
Z=\frac{m_{\mathrm{LPG}}}{m_{\mathrm{LPG}}+m_{\text {pilot fuel }}} \times 100 \% .
$$

2.2. Production of Karanja Oil Methyl Ester. Karanja oil meth$\mathrm{yl}$ ester (KOME) is prepared in the laboratory from neat Karanja (Pongamia pinnata) vegetable oil. The extracted vegetable oil is obtained from a local oil mill. For neat Karanja oil, the free fatty acid (FFA) is more than $5 \%$. So the FFA is reduced by acid catalyzed esterification using methanol in the presence of sulphuric acid $\left(\mathrm{H}_{2} \mathrm{SO}_{4}\right)$ followed by transesterification using methanol in the presence of potassium hydroxide $(\mathrm{KOH})$. After separation of glycerol, the ester is washed with water to remove unreacted methoxide. It is then heated to remove the water traces to obtain the clean

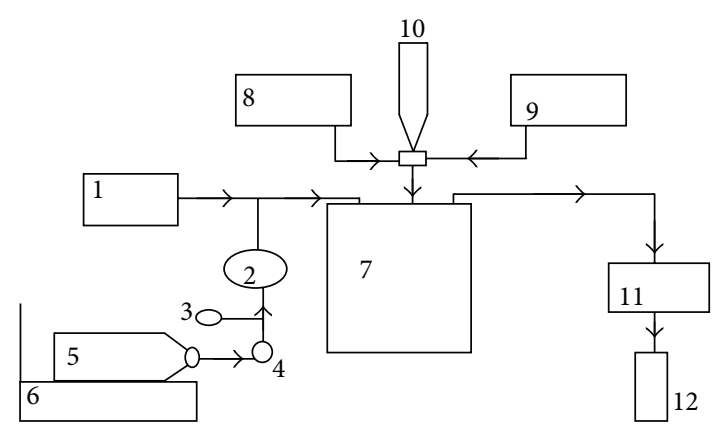
(1) Air filter
(2) Vaporizer
(3) Pressure gauge
(4) Fuel control value
(5) LPG tank
(6) Weighing machine
(7) Engine
(8) Diesel tank
(9) Biodiesel tank
(10) Burette
(11) Gas analyzer
(12) Exhaust muffler

FIgURE 1: Experimental layout diagram.

biodiesel. The Karanja oil methyl ester known as biodiesel, thus, produced by this process is totally miscible with diesel in any proportion [9].

\section{Results and Discussion}

The variations of performance and emission parameters with LPG flow rate are discussed in this section. As previous researches indicated that blends of biodiesel up to $20 \%$ show better performance as well as improved emission characteristics, while with higher blends the reduction in calorific value hampers the performance of the engine [9]. The properties of the fuels are shown in Table 3.

3.1. Brake Specific Fuel Consumption. Brake specific fuel consumption of the dual fuel mode is recorded with diesel and blends of biodiesel. A comparison of BSFC at $70 \%$ load for diesel and blends of KOME up to 20\% was presented in Figure 2. It is observed that by increasing load BSFC decreases, as with increase in load cylinder pressure and temperature increases, which improves the combustion process resulting in decrease in BSFC. The BSFC increases with increasing percentage of LPG substitution at part loads may be due to incomplete combustion of the gaseous fuel, while at higher loads BSFC improves with the increase of LPG substitution. On the other hand, BSFC gradually decreases with the increase in percentage of blend. This may be attributed to the presence of additional molecular oxygen present in biodiesel which improves the combustion process. A comparison of BSFC with increase in load is done at $4 \mathrm{~g} / \mathrm{min}$ flow rate of LPG was shown in Figure 3. It is observed that the BSFC decreases with increase in load. 20\% blend of KOME (B-20) shows lowest BSFC followed by $10 \%$ blend of KOME (B-10) and diesel over the whole load range. As the LPG flow rate was kept constant so B-10 and B-20 show a more improved BSFC than diesel. 
TABLE 2: Measurement range and accuracy of AVL 444 gas analyzer.

\begin{tabular}{|c|c|c|c|}
\hline Measured quality & Measuring range & Resolution & Accuracy \\
\hline $\mathrm{CO}$ & $0-10 \%$ vol. & $0.01 \%$ vol. & $\begin{array}{c}<0.6 \% \text { vol: } \pm 0.03 \% \text { vol. } \\
\geq 0.6 \% \text { vol: } \pm 5 \% \text { of ind value }\end{array}$ \\
\hline $\mathrm{CO}_{2}$ & $0-20 \%$ vol. & $0.1 \%$ vol. & $\begin{array}{l}<10 \% \text { vol: } \pm 0.5 \% \text { vol. } \\
\geq 10 \% \text { vol: } \pm 5 \% \text { vol. }\end{array}$ \\
\hline $\mathrm{HC}$ & $0-20000 \mathrm{ppm}$ vol & $\begin{array}{l}\leq 2000: 1 \text { ppm vol. } \\
>2000: 10 \text { ppm vol. }\end{array}$ & $\begin{array}{c}<200 \text { ppm vol: } \pm 10 \text { ppm vol. } \\
\geq 200 \text { ppm vol: } \pm 5 \% \text { of ind. val. }\end{array}$ \\
\hline $\mathrm{O}_{2}$ & $0-22 \%$ vol. & $0.01 \%$ vol. & $\begin{array}{l}<2 \% \text { vol: } \pm 0.1 \% \text { vol. } \\
\geq 2 \% \text { vol: } \pm 5 \% \text { vol. }\end{array}$ \\
\hline $\mathrm{NO}$ & 0-5000 ppm vol. & 1 ppm vol. & $\begin{array}{c}<500 \text { ppm vol: } \pm 50 \text { ppm vol. } \\
\geq 500 \text { ppm vol: } \pm 10 \% \text { of ind. val. }\end{array}$ \\
\hline Engine speed & $400-6000 \mathrm{~min}^{-1}$ & $1 \min ^{-1}$ & $\pm 1 \%$ of ind. val. \\
\hline Oil temperature & $-30-125^{\circ} \mathrm{C}$ & $1^{\circ} \mathrm{C}$ & $\pm 4^{\circ} \mathrm{C}$ \\
\hline Lambda & $0-9.999$ & 0.001 & Calculation of $\mathrm{CO}, \mathrm{CO}_{2}, \mathrm{HC}, \mathrm{O}_{2}$ \\
\hline
\end{tabular}

TABLE 3: Fuel properties.

\begin{tabular}{lccccc}
\hline Fuel & Sp.gravity & Kinematic viscosity $(\mathrm{cSt})$ at $40^{\circ} \mathrm{C}$ & Flash point $\left({ }^{\circ} \mathrm{C}\right)$ & Calorific value $(\mathrm{MJ} / \mathrm{kg})$ & $\mathrm{Cetane}$ number \\
\hline Standard diesel & 0.832 & 1.9 & 64 & 42.21 & 36.12 \\
KOME & 0.885 & 4.5249 & 187 & 41.582 & -55 \\
B-10 & 0.837 & 2.1831 & 72 & 40.911 & - \\
B-20 & 0.843 & 2.4164 & 79 & 46.200 & - \\
LPG & 0.562 & - & -105 & $<3$ \\
\hline
\end{tabular}

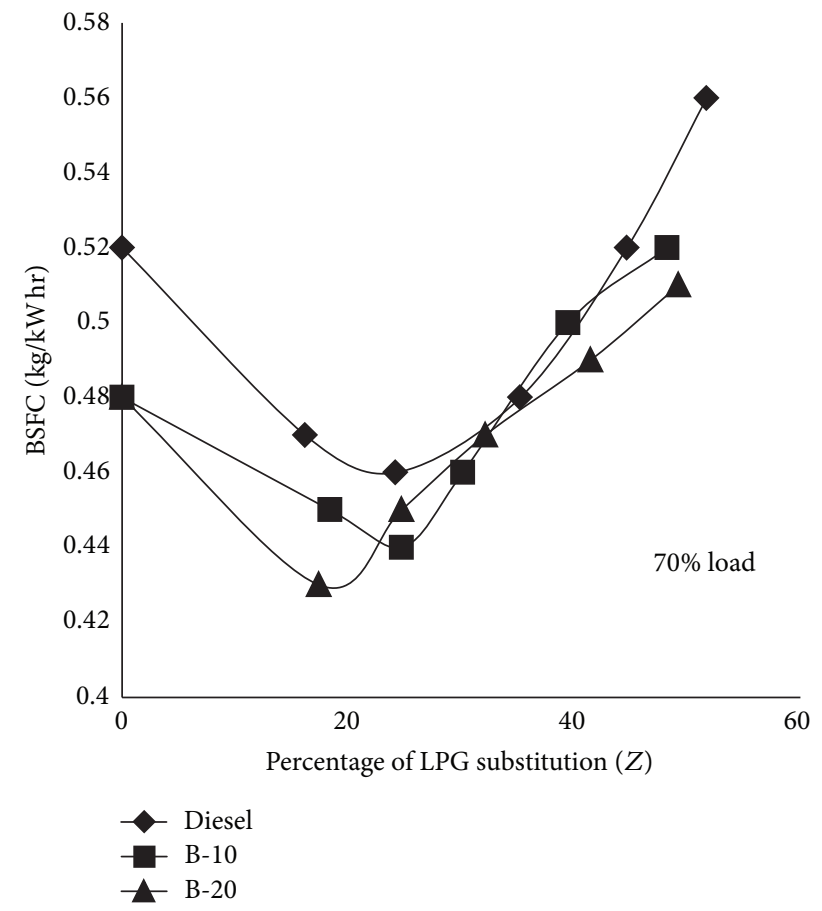

FIGURE 2: Comparison of variation of BSFC with percentage of substitution of LPG.

3.2. Brake Thermal Efficiency. Brake thermal efficiency (BTE) of all the pilot fuels are observed in dual fuel mode. The comparison of BTE for diesel B-10 and B-20 at 70\% load was shown in Figure 4. It is found that B-10 and B-20 give better BTE at all loads as compared to standard diesel. This may be attributed to extra oxygen content of biodiesel blends which improves the combustion process tending to increase in BTE of the engine. But with increase in substitution of LPG the BTE gradually falls for all the pilot fuels at part load conditions, because at low loads less pilot fuel is impinged into the cylinder, and due to the excess air and low cylinder temperature, lean amount of fuel mixture escapes into the exhaust. While for diesel, BTE increases at higher load up to $35 \%$ of LPG substitution. At higher load the increase in average gas temperature has the effect of reducing the fuel ignition delay resulting in an improved BTE. A comparison of BTE with increase in load for all the pilot fuel at $4 \mathrm{~g} / \mathrm{min}$ flow rate of LPG was shown in Figure 5. It is observed that the BTE increases with increase in load, while blends of B-10 and B-20 give better BTE at all loads as compared to standard diesel. This may be attributed to extra oxygen content of biodiesel blends which improves the combustion process tending to increase in BTE of the engine.

3.3. HC Emissions. HC emissions consist of fuel that is completely unburned or partially burned. Typically, HC emissions are serious problems at light loads for diesel engines. The comparison of $\mathrm{HC}$ emissions of all the pilot fuels in dual fuel mode was shown in Figure 6. In dual fuel mode with increase in substitution of LPG, the HC emission increases. This may be due to reduction in fresh air with increase in LPG flow rate which results in incomplete combustion of the richer mixture. $\mathrm{HC}$ emission level decreases with the increase 


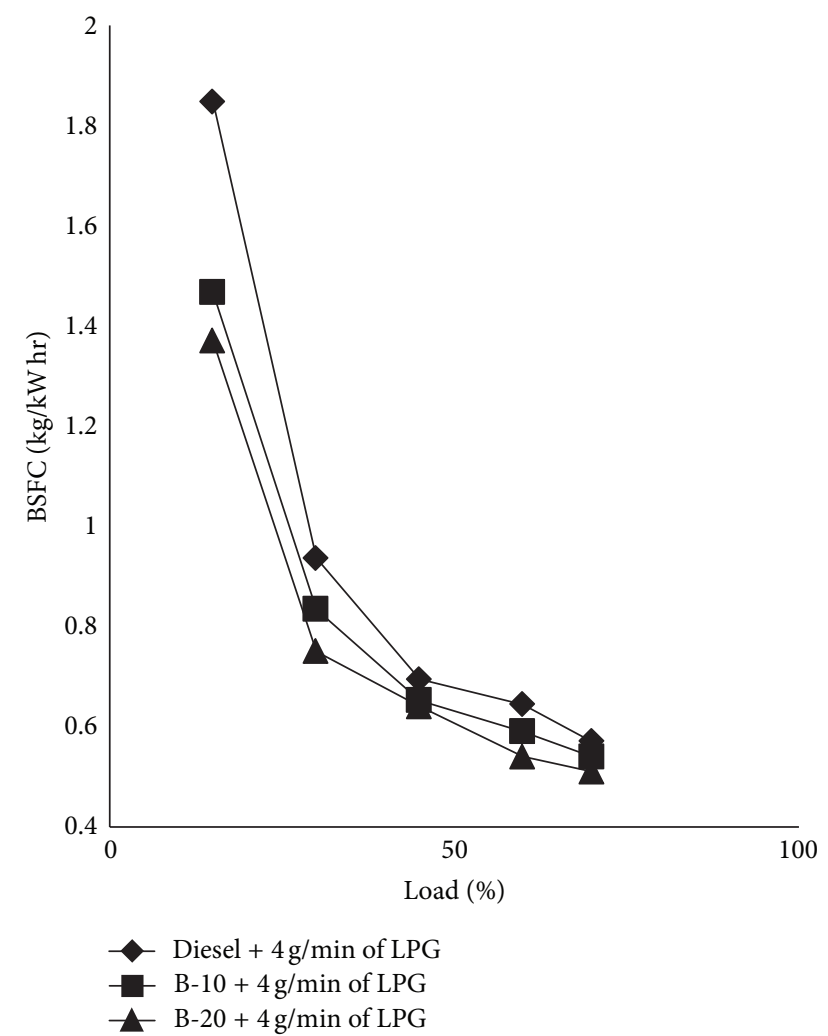

FIGURE 3: Comparison of BSFC with increase in percentage of load.

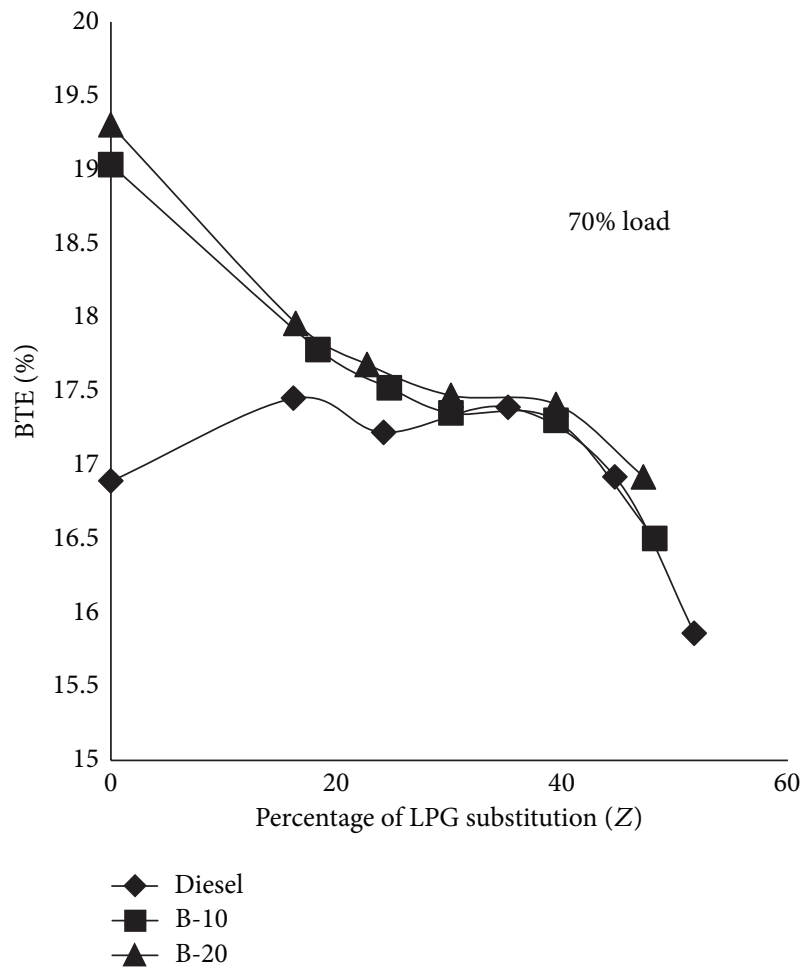

FIGURE 4: Comparison of variation BTE with percentage of substitution of LPG.

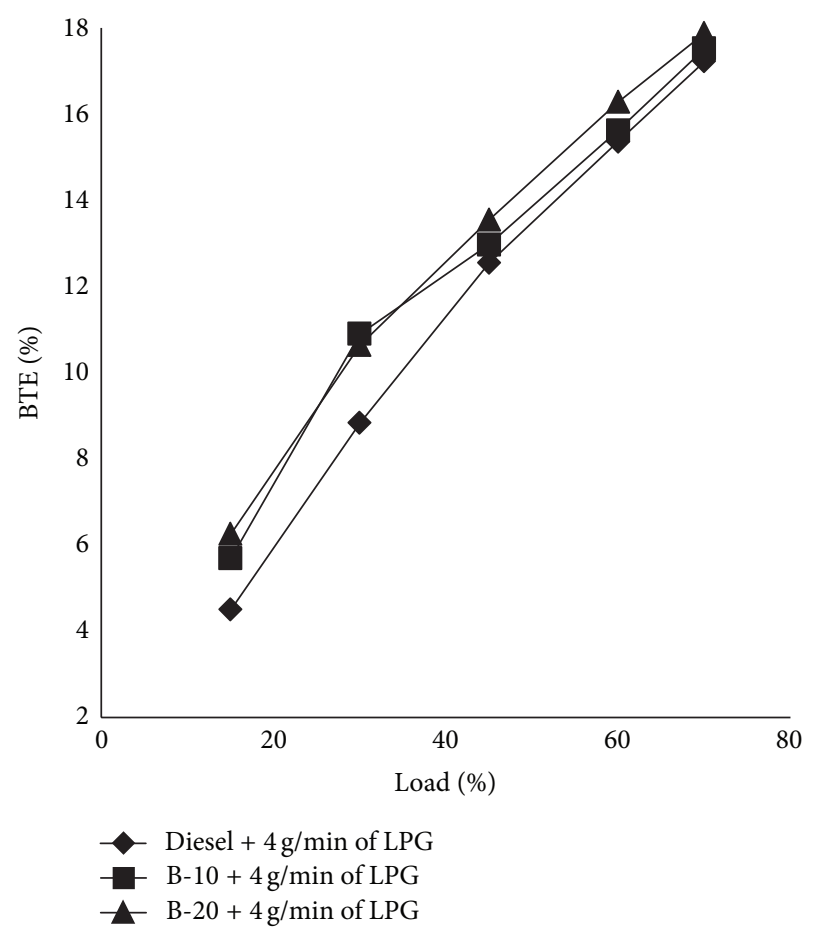

FIgURE 5: Comparison of BTE with increase in percentage of load.

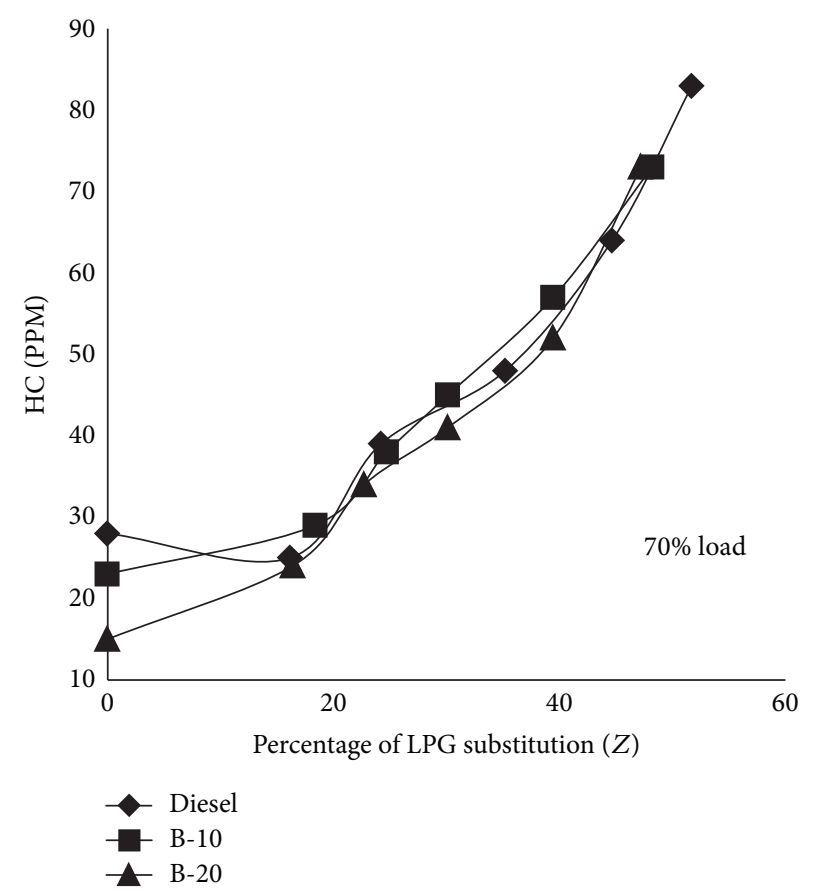

FIGURE 6: Comparison of variation HC emission with percentage of LPG substitution.

in biodiesel blends. The decreased trend of HC emissions compared to diesel fuel might be due to presence of oxygen molecules in biodiesel which helped in complete combustion. At $4 \mathrm{~g} / \mathrm{min}$ flow rate of LPG, the observation showed that HC emission gradually decreases with increase in load. It may be due to the low engine temperature and lean mixture as part 


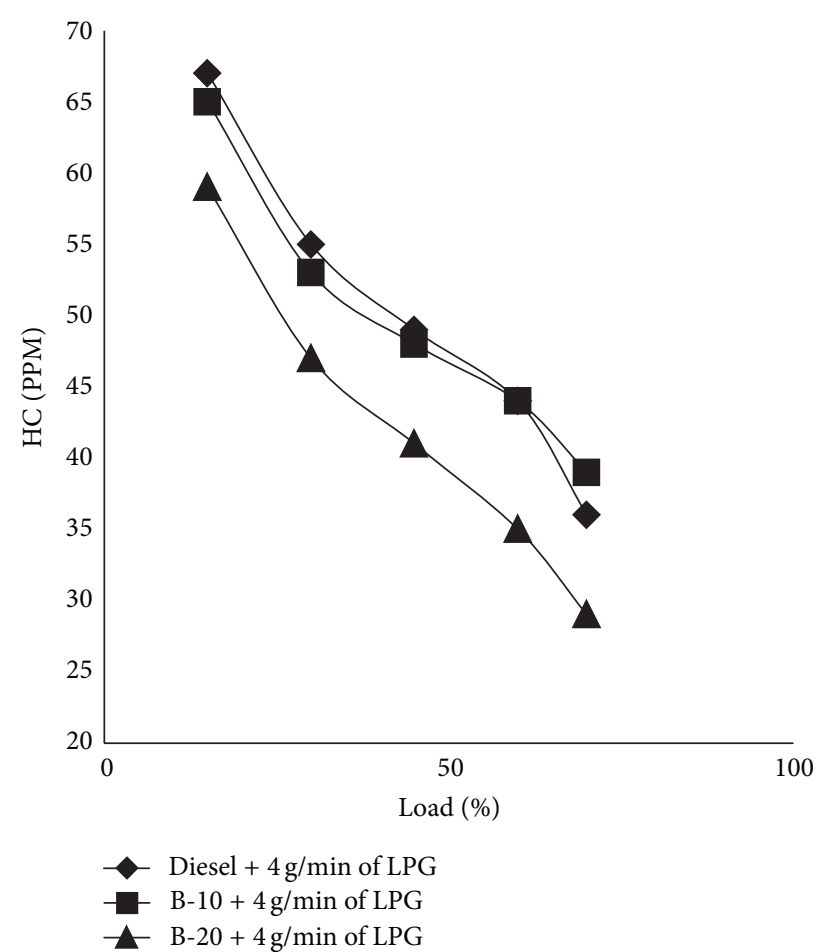

FIGURE 7: Comparison of HC emission with increase in percentage of load.

loads affects the combustion of air fuel mixture and few of it escapes into the exhaust. While at higher load with increase in peak cylinder temperature, proper combustion takes place which reduces the $\mathrm{HC}$ emission. The result was illustrated in Figure 7. The HC emission was highest for diesel followed by B-10 and B-20.

3.4. $\mathrm{NO}_{x}$ Emissions. $\mathrm{NO}_{x}$ is the most harmful gaseous emissions from engines. $\mathrm{NO}_{x}$ formation rate strongly depends upon in-cylinder gas temperature. Hence, the fuel distribution within the cylinder and its combustion process affect the $\mathrm{NO}_{x}$ formation. Generally $\mathrm{NO}_{x}$ forms at the high temperature burned gas regions. The comparison of variations of $\mathrm{NO}_{x}$ emission with LPG substitution was shown in Figure 8. The $\mathrm{NO}_{x}$ emission decreases with the increase in LPG flow rate. This may be attributed to reduction in fresh air and high self ignition temperature of LPG, which increases the ignition delay resulting into reduced peak cylinder temperature. On the other hand, $\mathrm{NO}_{x}$ emission increases with increase in blend percentage of biodiesel because oxygen content of biodiesel provides high local temperature which improves combustion process. The variation of $\mathrm{NO}_{x}$ emission with load at $4 \mathrm{~g} / \mathrm{min}$ of LPG flow rate for diesel, B-10 and B-20, was shown in Figure 9. It was observed that B-20 shows the highest $\mathrm{NO}_{x}$ emission followed by B-10 and standard diesel.

3.5. CO Emissions. Generally, $\mathrm{CO}$ emission from the engine occurs due to partial oxidation of the fuel mixture. As it is well known that the rate of $\mathrm{CO}$ formation is a function of unburned fuel and mixture temperature during combustion,

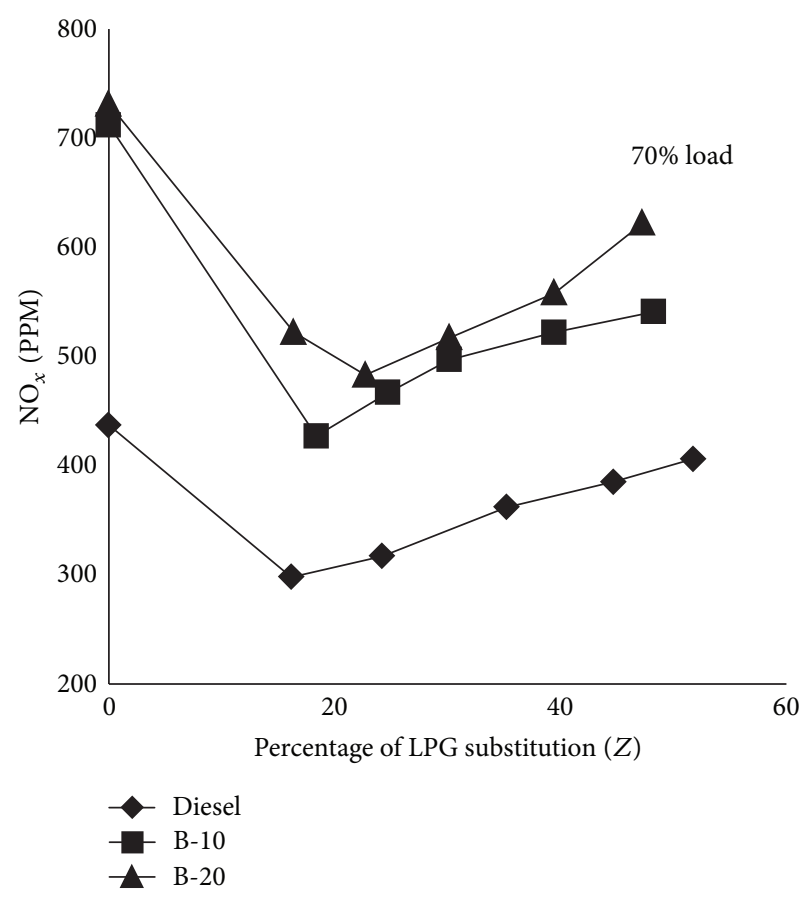

FIGURE 8: Comparison of variation of $\mathrm{NO}_{x}$ emission with percentage of LPG substitution.

since both factors control the fuel decomposition and oxidation. The variations of CO emission with LPG substitution were shown in Figure 10. It is observed that with increase in substitution of LPG, initially the CO emission decreases up to $25 \%$ of substitution for all the three pilot fuels. But with further increase in LPG flow rate the CO emission increases; may be due to reduction in fresh oxygen leads to partial oxidation of the fuel mixture. With the increase in proportion of blend, $\mathrm{CO}$ emission is found to be decreasing. This shows that maybe due to presence of extra oxygen in blends as compared to neat diesel proper oxidation of the blends results in lower $\mathrm{CO}$ emission. At $4 \mathrm{~g} / \mathrm{min}$ flow rate of LPG the observation shows that CO emission gradually decreases by increasing load. It may be due to the low engine temperature and lean mixture at part loads, the whole air fuel mixture does not burn completely and few of it escapes into the exhaust. The $\mathrm{CO}$ emission was highest for diesel followed by B-10 and B-20. The result was shown in Figure 11.

\section{Conclusion}

In the present work, an experimental investigation has been conducted to examine the effects of induction of LPG into the engine manifold (just adjacent to inlet valve) with KOME as the pilot fuel. From the analysis of the experimental data, it is observed that BSFC and BTE improved for the CI engine with B-10 and B-20 as compared with diesel. While at part load, the BSFC increases as well as BTE decreases with increase in LPG substitution, but an improvement was observed for both the parameters at higher loads. The HC and $\mathrm{CO}$ emissions were increased in dual fuel mode. But blends 


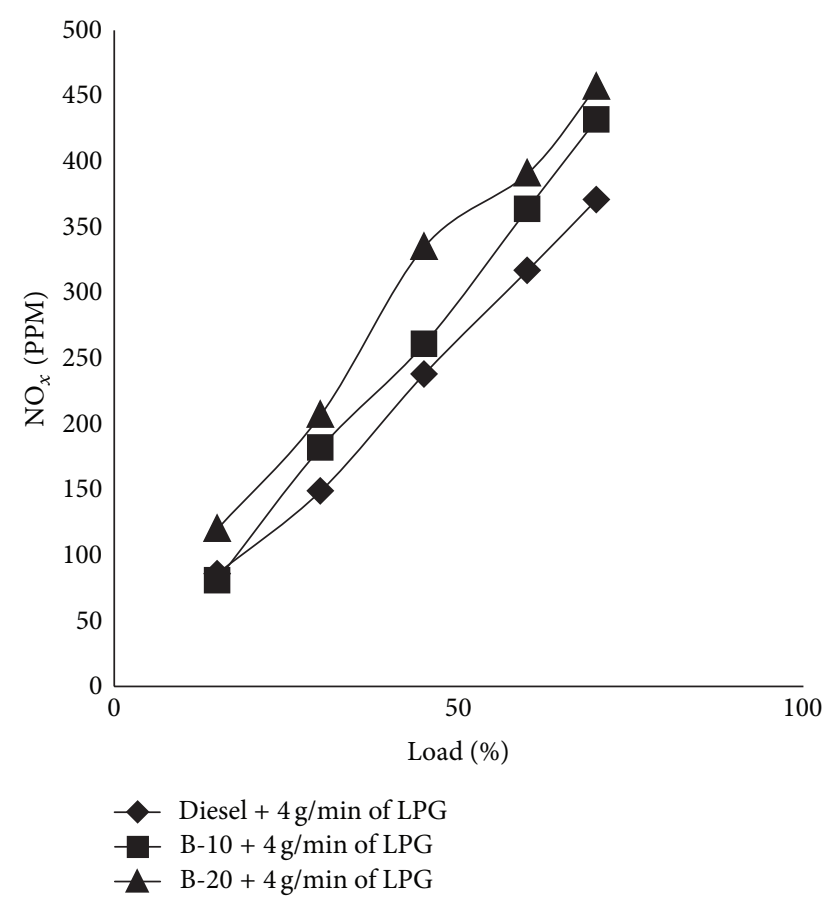

FIGURE 9: Comparison of $\mathrm{NO}_{x}$ emission with increase in percentage of load.

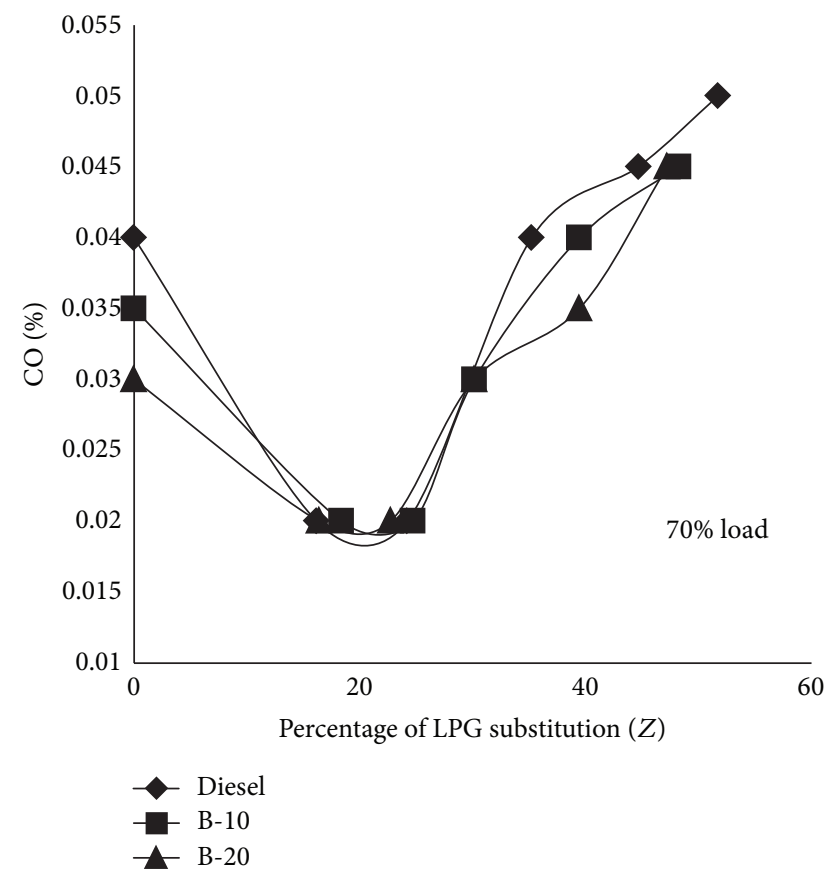

FIGURE 10: Comparison of variation of $\mathrm{CO}$ emission with percentage of LPG substitution.

of KOME have shown reduced $\mathrm{HC}$ and $\mathrm{CO}$ emissions in dual fuel mode as compared with diesel. The $\mathrm{NO}_{x}$ emission was reduced in dual fuel mode for all the three pilot fuels, while with increase in blend percentage of KOME an increase in $\mathrm{NO}_{x}$ emission was observed. Higher blends of KOME have higher viscosity, which affects the atomization of the pilot

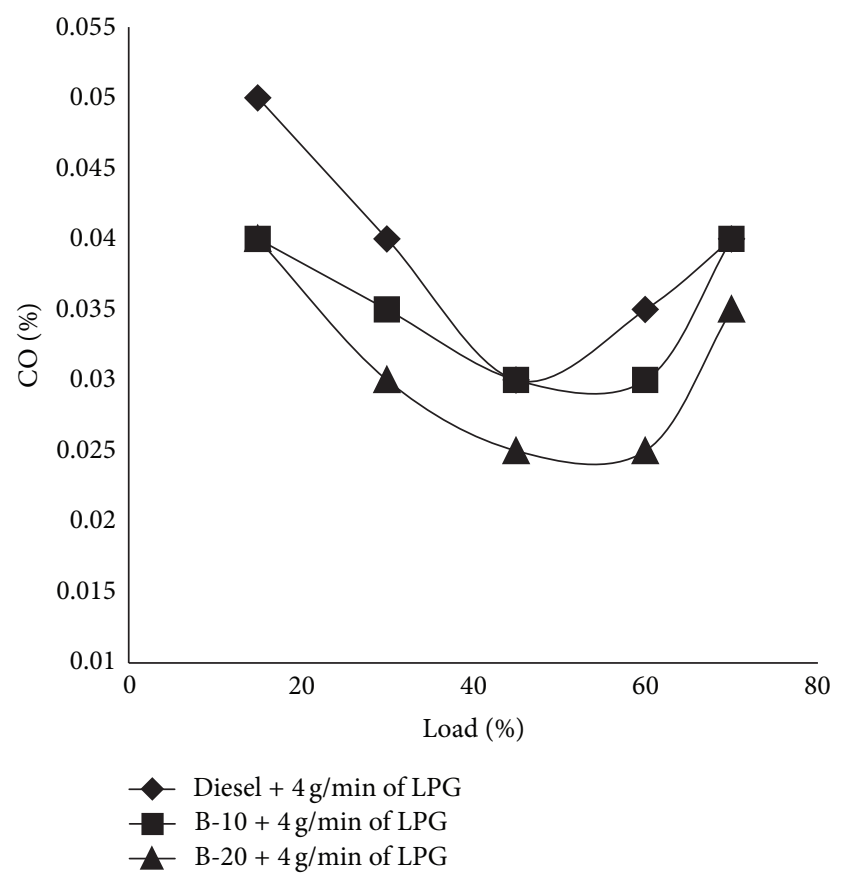

FIgURE 11: Comparison of $\mathrm{CO}$ emission with increase in percentage of load.

fuel. Further improvement of the performance and emissions characteristics in dual fuel mode with higher blends can be possible by increasing the injection pressure.

\section{References}

[1] M. Y. E. Selim, M. S. Radwan, and H. E. Saleh, "Improving the performance of dual fuel engines running on natural gas/LPG by using pilot fuel derived from jojoba seeds," Renewable Energy, vol. 33, no. 6, pp. 1173-1185, 2008.

[2] I. D. Bedoya, A. A. Arrieta, and F. J. Cadavid, "Effects of mixing system and pilot fuel quality on diesel-biogas dual fuel engine performance," Bioresource Technology, vol. 100, no. 24, pp. 66246629, 2009.

[3] G. A. Rao, A. V. S. Raju, K. G. Rajulu, and C. V. M. Rao, "Performance evaluation of a dual fuel engine (Diesel + LPG)," Indian Journal of Science and Technology, vol. 3, no. 3, pp. 235-238, 2010.

[4] C. C. M. Luijten and E. Kerkhof, "Jatropha oil and biogas in a dual fuel CI engine for rural electrification," Energy Conversion and Management, vol. 52, no. 2, pp. 1426-1438, 2011.

[5] S. H. Yoon and C. S. Lee, "Experimental investigation on the combustion and exhaust emission characteristics of biogasbiodiesel dual-fuel combustion in a CI engine," Fuel Processing Technology, vol. 92, no. 5, pp. 992-1000, 2011.

[6] D. Agarwal, S. Sinha, and A. K. Agarwal, "Experimental investigation of control of $\mathrm{NO}_{x}$ emissions in biodiesel-fueled compression ignition engine," Renewable Energy, vol. 31, no. 14, pp. 2356-2369, 2006.

[7] A. Murugesan, C. Umarani, R. Subramanian, and N. Nedunchezhian, "Bio-diesel as an alternative fuel for diesel engines-a review," Renewable and Sustainable Energy Reviews, vol. 13, no. 3, pp. 653-662, 2009. 
[8] A. S. Ramadhas, S. Jayaraj, and C. Muraleedharan, "Dual fuel mode operation in diesel engines using renewable fuels: rubber seed oil and coir-pith producer gas," Renewable Energy, vol. 33, no. 9, pp. 2077-2083, 2008.

[9] S. Jindal, "Experimental investigation of the effect of compression ratio and injection pressure in a direct injection diesel engine running on Karanj methyl ester," International Journal of Sustainable Energy, vol. 30, supplement 1, pp. S91-S105, 2011.

[10] C. V. Sudhir, V. Desai, Y. Suresh Kumar, and P. Mohanan, "Studies on influence of injection timing and diesel replacement on LPG-diesel dual-fuel engine," in Proceedings of the Internal Combustion Engine and Rail Transportation Divisions Fall Technical Conference (ICERT '03), pp. 161-166, September 2003.

[11] D. H. Qi, Y. Z. Bian, Z. Y. Ma, C. H. Zhang, and S. Q. Liu, "Combustion and exhaust emission characteristics of a compression ignition engine using liquefied petroleum gas-Diesel blended fuel," Energy Conversion and Management, vol. 48, no. 2, pp. 500-509, 2007.

[12] M. P. Poonia, A. Bhardwaj, A. S. Jethoo, and U. Pandel, "Experimental investigation on engine performance and exhaust emissions in an LPG diesel dual fuel engine," International Journal of Environmental Science and Development, vol. 2, no. 6, pp. 418422, 2011. 


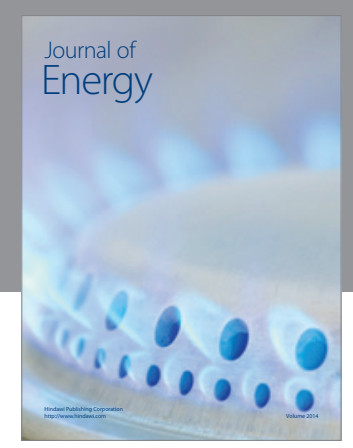

Journal of

Industrial Engineering
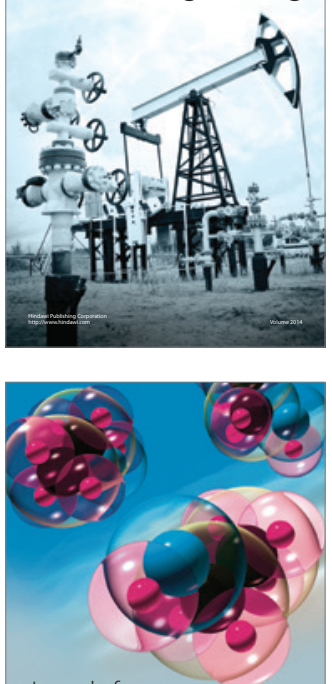

Fuels
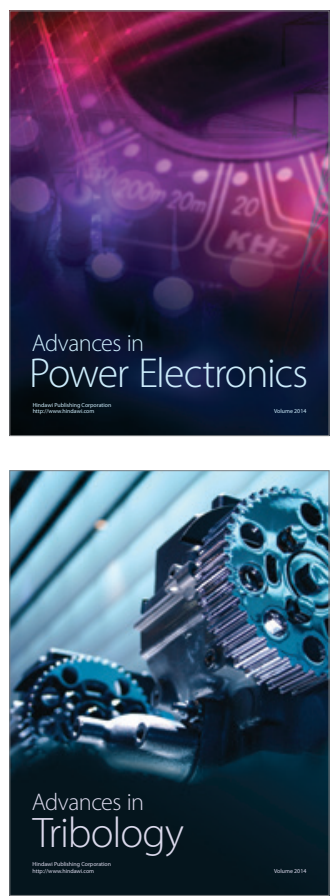

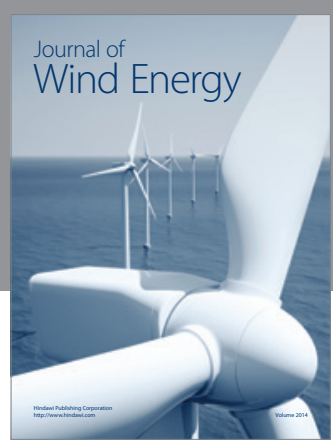

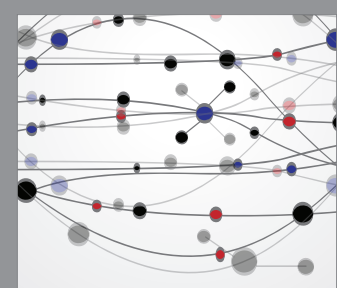

The Scientific World Journal

Submit your manuscripts at http://www.hindawi.com

Journal of

Structures
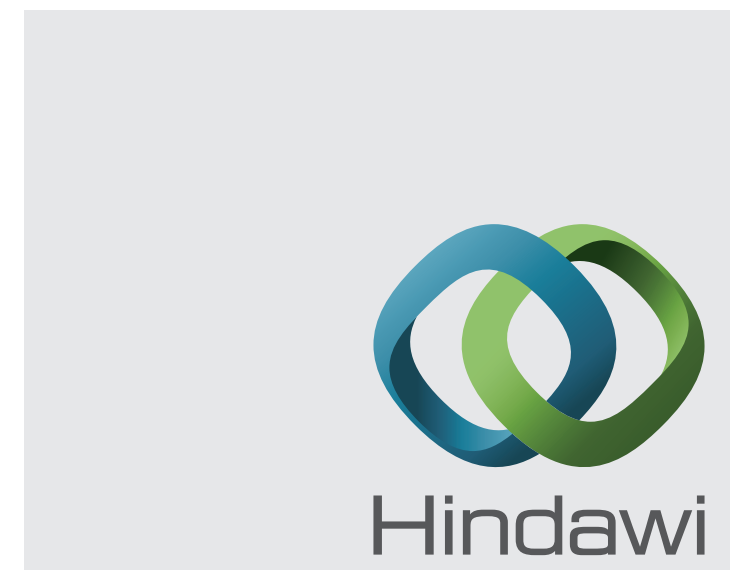

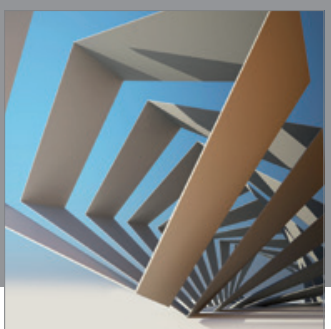

Rotating

Machinery
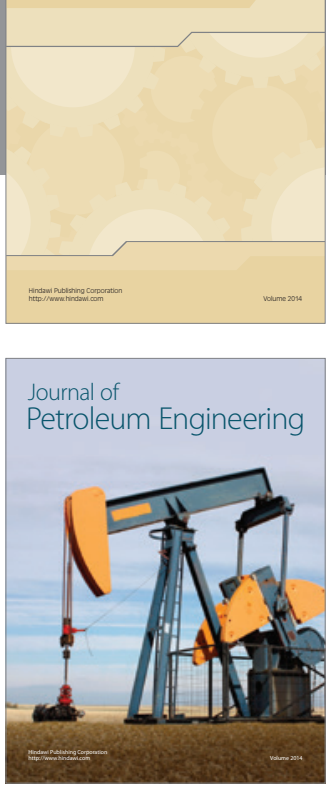

Journal of

Solar Energy
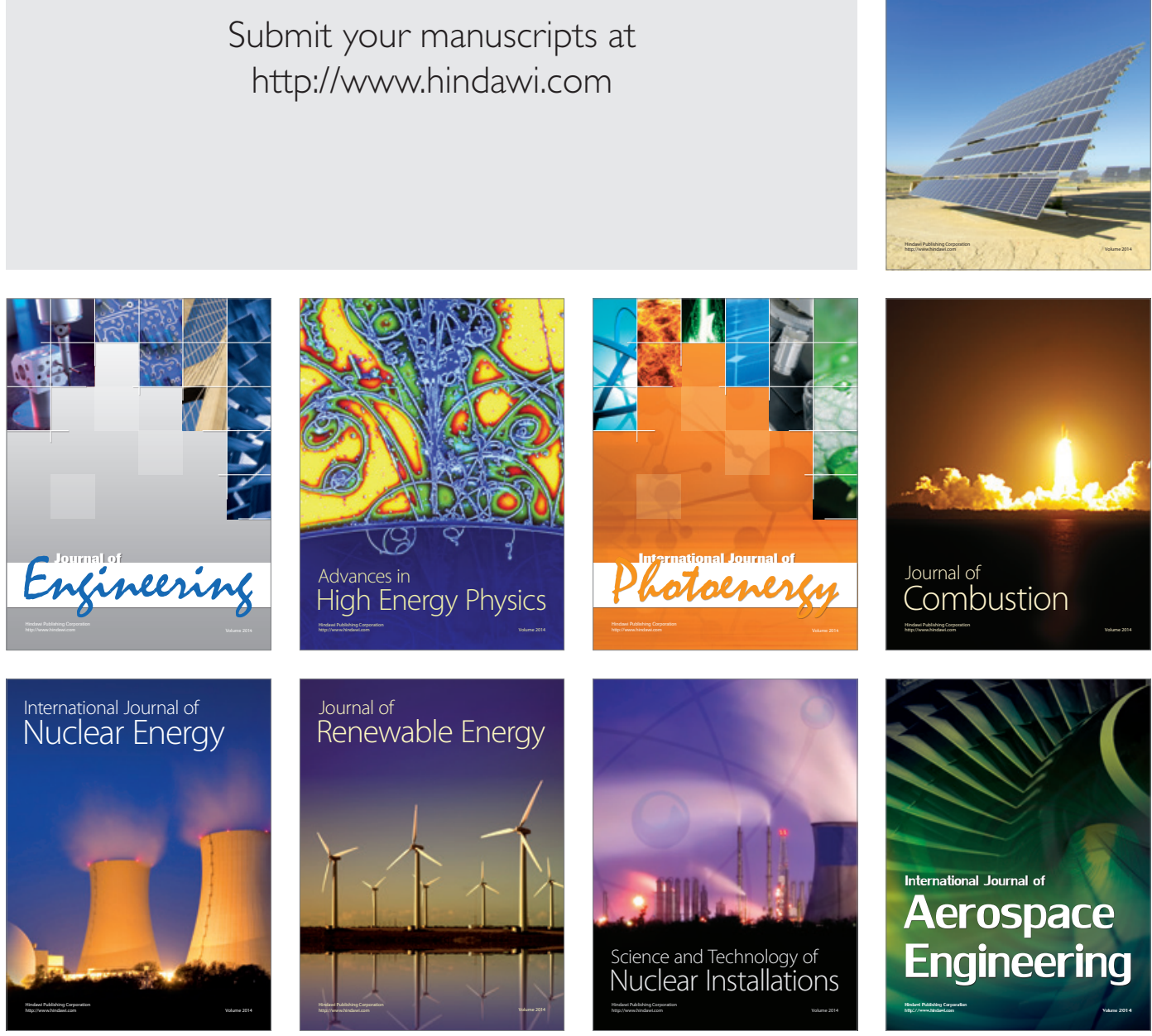